\title{
Comment on "Microsurgical Techniques Used to Construct the Vascularized and Neurotized Tissue Engineered Bone"
}

\author{
Annika Weigand, Justus P. Beier, Andreas Arkudas, Raymund E. Horch, and Anja M. Boos \\ Department of Plastic and Hand Surgery, University Hospital of Erlangen, Friedrich-Alexander University of Erlangen-Nürnberg, \\ Krankenhausstraße 12, 91054 Erlangen, Germany
}

Correspondence should be addressed to Annika Weigand; annika.weigand@uk-erlangen.de

Received 23 February 2015; Accepted 20 April 2015

Academic Editor: Aijun Wang

Copyright (C) 2015 Annika Weigand et al. This is an open access article distributed under the Creative Commons Attribution License, which permits unrestricted use, distribution, and reproduction in any medium, provided the original work is properly cited.

We read with great interest the review article by Fan et al. [1] that discusses a range of microsurgical techniques used for vascularization and neurotization in bone tissue engineering. Not only the lack of vascularization but also the lack of neurotization within tissue engineered bone can lead to insufficient ossification resulting in treatment failure.

Since we have been working in the research area of vascularized bone tissue engineering for many years, we are aware of the problem of generating an optimal prevascularized scaffold for large and poorly vascularized bone defects. One of the main obstacles remains an adequate vascularization and thus survival of implanted cells or, with regard to the manuscript by Fan et al., of nerve tracts, especially in the center of scaffolds.

As mentioned by Fan et al. in a range of studies it could be demonstrated that sensory nerve innervation can contribute to bone integrity and bone formation [2-4]. Chen et al. demonstrate that sensory nerves could enhance the osteogenesis of tissue engineered bone. Sensory nerves or blood vessels were implanted with a scaffold directly in the defect site [3]. Fan et al. emphasize that an optimal support with oxygen and nutrients is of fundamental importance for the survival of the neurocytes. For optimization and constructing the vascularized and neurotized tissue engineered bone simultaneously both blood vessel and the nerve tract should be implanted together in the bone graft [1].

Another way for engineering vascularized tissue is the prevascularization of constructs distant to the injury site in unharmed areas of the body using the intrinsic vascularization with an arteriovenous (AV) loop that was firstly described by Erol and Spira [5]. After a sufficient prevascularization period osteogenic cells such as osteoblasts or nerve tracts can be implanted without being lost through inadequate supply of oxygen or nutrients. Tissue engineered constructs can afterwards be microsurgically transplanted in the defect site independent of the local vasculature. In a previously performed study in the rat AV loop model space holders were placed in the scaffold during the prevascularization period, leaving holes for subsequent injection of CFDAlabeled osteoblasts. A significantly higher number of CFDApositive cells and a higher expression of bone specific markers were detected in the prevascularized scaffolds compared to control, indicating this technique to be well suited to support bone formation and the probable survival of implanted cells.

Nevertheless, moving from bench to bedside, the large animal sheep AV loop model was established, and we were able to generate intrinsically vascularized tissue in a clinically relevant size (volume $15 \mathrm{~cm}^{3}$ ). For faster vascularization and consequently better nutritional support of implanted cells, we modified the AV loop model using a perforated chamber. Combining extrinsic and intrinsic vascularization, enhancement of angiogenesis could be demonstrated in the small and large animal [6] (Figure 1). Connection between both vascular pathways allows the microsurgical transplantation of the vascularized bone construct. Based on the results of our studies, we have previously used the AV loop successfully for the reconstruction of large bone defects in two patients [7]. 


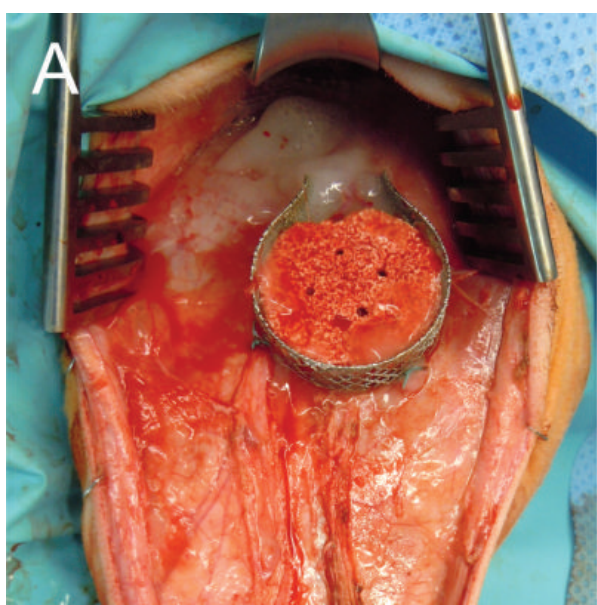

(a)

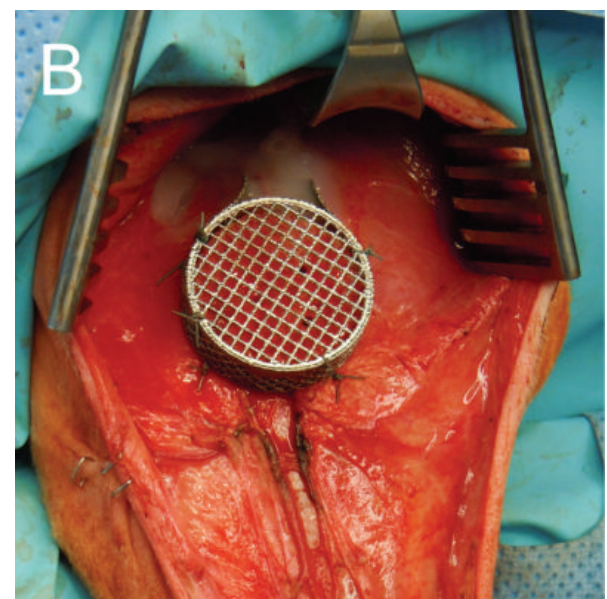

(b)

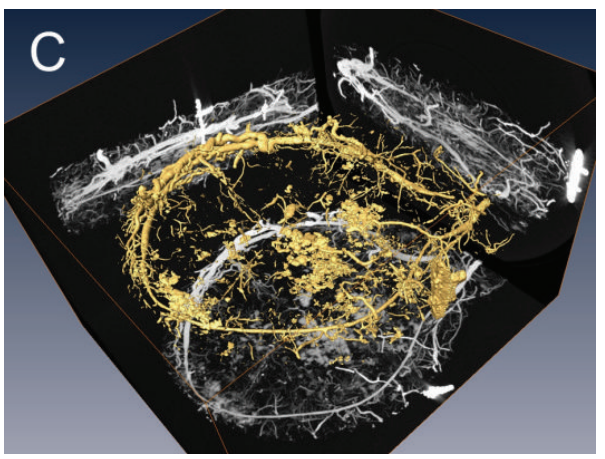

(c)

Figure 1: Arteriovenous loop model sheep. ((a)-(b)) Implantation of a primary stable bone substitute within a perforated titanium chamber allowing combined intrinsic-extrinsic vascularization of the scaffold. (c) After explantation vessels were perfused with a contrast agent and visualized using micro-CT.

To pave the way for further preclinical testing, the efficient implantation of a sensor nerve tract by Fan et al. should be proofed in a large animal and combined with the intrinsic-extrinsic large animal AV loop model. For minimizing hypoxic-dependent cell death, the nerve tract could be implanted after an adequate prevascularization period or close to AV loop vessels. We agree with Fan et al. that further studies must be performed to find efficient therapies for large and complicated bone defects, in order to make wide clinical application possible.

\section{Conflict of Interests}

The authors declare that there is no conflict of interests regarding the publication of this paper.

\section{Acknowledgment}

The authors would like to thank PD Dr. Andreas Hess, Institute of Experimental and Clinical Pharmacology and Toxicology, Friedrich-Alexander University of ErlangenNürnberg, Erlangen, Germany, for his excellent work on three-dimensional imaging and providing them with the micro-CT image (Figure 1(c)).

\section{References}

[1] J. Fan, L. Bi, D. Jin et al., "Microsurgical techniques used to construct the vascularized and neurotized tissue engineered bone," BioMed Research International, vol. 2014, Article ID 281872, 7 pages, 2014.

[2] Y. Ding, M. Arai, H. Kondo, and A. Togari, "Effects of capsaicininduced sensory denervation on bone metabolism in adult rats," Bone, vol. 46, no. 6, pp. 1591-1596, 2010.

[3] S.-Y. Chen, J.-J. Qin, L. Wang et al., "Different effects of implanting vascular bundles and sensory nerve tracts on the expression of neuropeptide receptors in tissue-engineered bone in vivo," Biomedical Materials, vol. 5, no. 5, Article ID 55002, 2010.

[4] S. C. Offley, T.-Z. Guo, T. Wei et al., "Capsaicin-sensitive sensory neurons contribute to the maintenance of trabecular bone integrity," Journal of Bone and Mineral Research, vol. 20, no. 2, pp. 257-267, 2005.

[5] O. O. Erol and M. Spira, "New capillary bed formation with a surgically constructed arteriovenous fistula," Surgical Forum, vol. 30 , pp. $530-531,1979$. 
[6] A. Weigand, J. P. Beier, A. Hess et al., "Acceleration of vascularized bone tissue-engineered constructs in a large animal model combining intrinsic and extrinsic vascularization," Tissue Engineering A, vol. 21, no. 9-10, pp. 1680-1694, 2015.

[7] R. E. Horch, J. P. Beier, U. Kneser, and A. Arkudas, "Successful human long-term application of in situ bone tissue engineering," Journal of Cellular and Molecular Medicine, vol. 18, no. 7, pp. 1478-1485, 2014. 


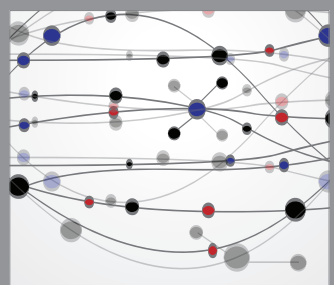

The Scientific World Journal
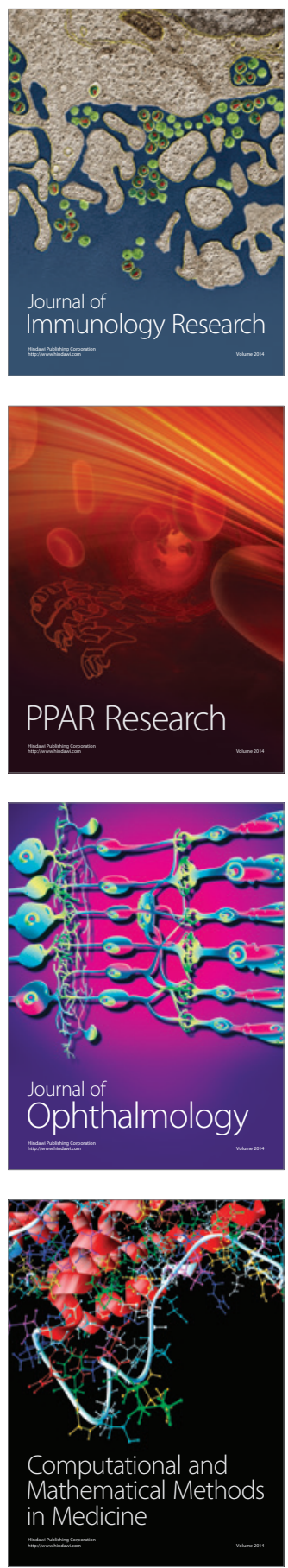

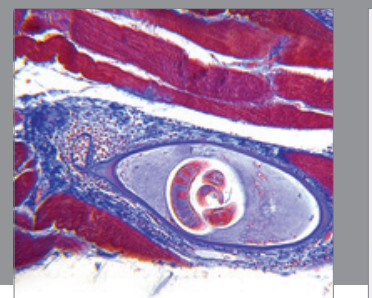

Gastroenterology

Research and Practice
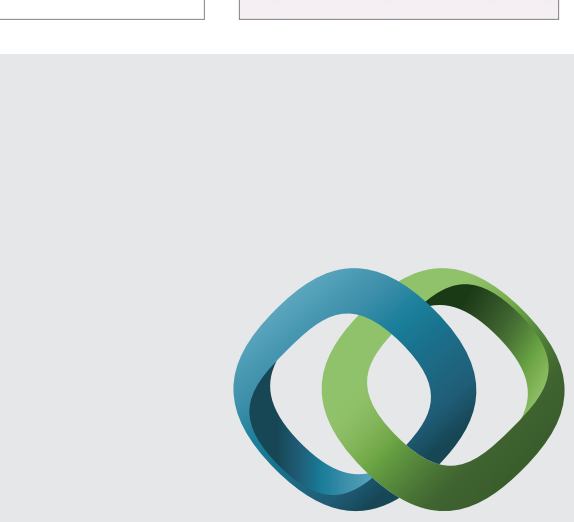

\section{Hindawi}

Submit your manuscripts at

http://www.hindawi.com
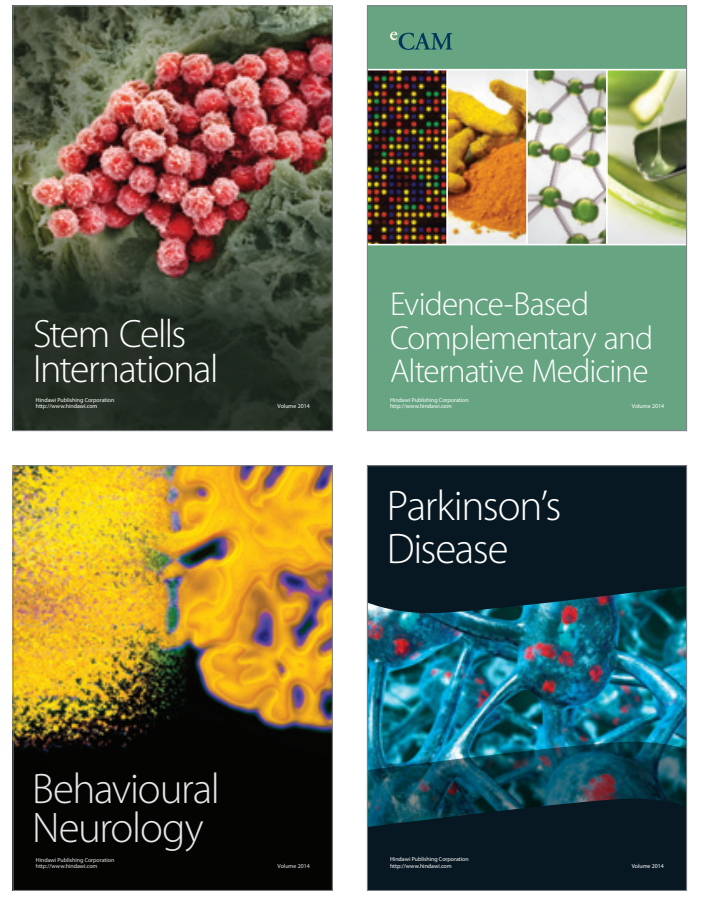
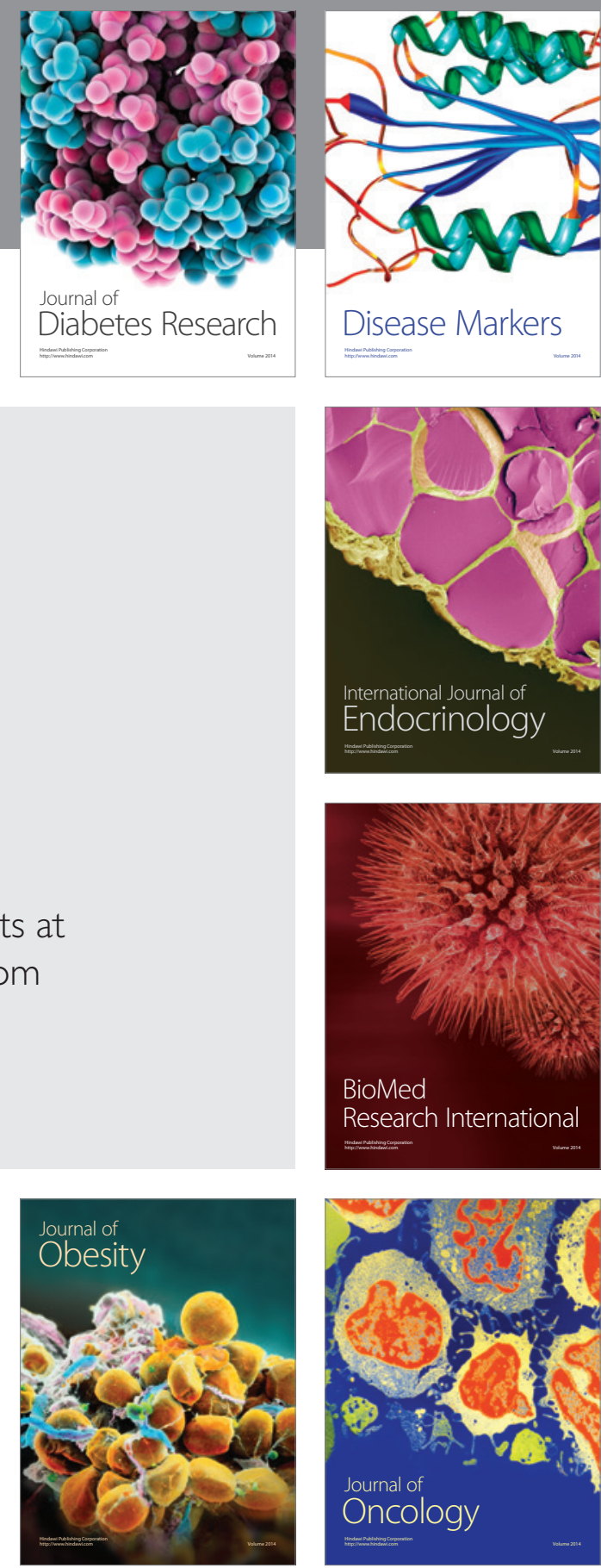

Disease Markers
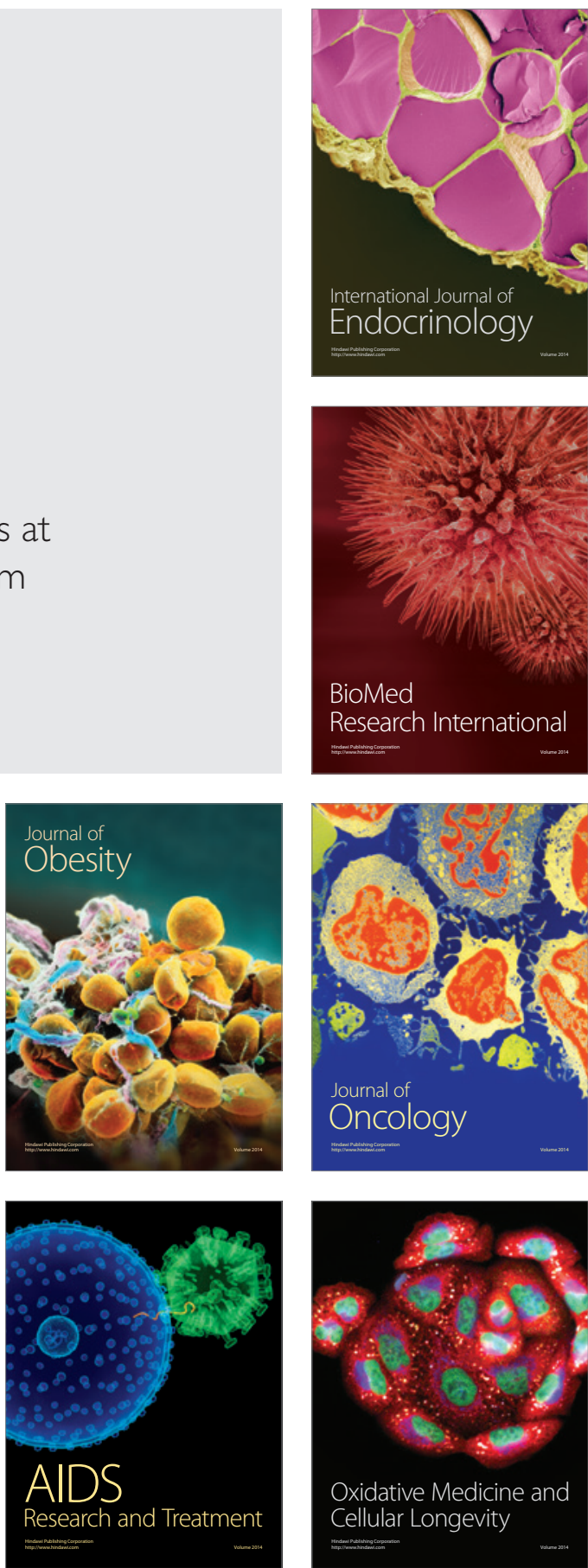